\title{
DE FRANKENSTEIN À CRIOGENIA: DANDO VIDA A CORPOS INANIMADOS
}

FROM FRANKENSTEIN TO CRYOGENIC: GIVING LIFE TO INANIMATED BODIES

\section{Ana Virgínia Gabrich Fonseca Freire Ramos ${ }^{1}$ \\ Luiza Machado Farhat Benedito ${ }^{2}$}

Resumo: Se antes a morte era evento futuro e certo, hoje, com os avanços da tecnologia essa afirmação é colocada em xeque. Por meio da técnica da criogenia humana, cientistas buscam congelar corpos para que, no futuro, as pessoas possam retornar à vida. Referida experiência, entretanto, envolve inúmeros questionamento éticos e jurídicos, principalmente no âmbito do direito sucessório. $\mathrm{O}$ artigo, busca analisar as consequências dessa nova situação, partindo de exemplos práticos e realizando um paralelo com a obra Frankenstein, de Mary Shelley. A metodologia utilizada, é a pesquisa exploratória apoiada em levantamento bibliográfico e estudo de caso. O método é hipotético-dedutivo.

Palavras-chave: Criogenia humana; Direito Sucessório; Ética; Responsabilidade; Testamento Vital.

Abstract: If before, the death was a future and certain event, today, with the advances of technology, this statement is put in check. Through the technique of human cryogenics, scientists seek to freeze bodies so that, in the future, people can return to life. Such experience, however, involves numerous ethical and legal questions, especially within the scope of sucession law. The article seeks to analyze the consequences of this new situation, starting with practical examples and paralleling Mary Shelley's work Frankenstein. The methodology used is exploratory research supported by a bibliographical survey and case study. The method is hypothetical-deductive.

\footnotetext{
${ }^{1}$ Professora da Escola Superior Dom Helder Câmara (DHC); Doutoranda em Direito pela DHC; Mestra em Direito pela DHC; Especialista em Direito Ambiental; Currículo Lattes: http://lattes.cnpq.br/2597814013605351 |E-mail: gabrichfreire@gmail.com

${ }^{2}$ Professora da FASEH; Mestra em Direito pela Universidade FUMEC; Pesquisadora no projeto de pesquisa Design Instrucional e Inovação das Metodologias de Ensino Jurídico (FAPEMIG); Especializada em Mediação (ICFML - OAB/MG). Currículo Lattes: http://lattes.cnpq.br/9301354857281204 | E-mail: luizafarhatprof@gmail.com
} 
Key-words: Human cryogenic; Succession Law; Ethic; Responsibility; Living Will. 


\section{INTRODUÇÃO}

Mary Shelley, em 1818, publica sua obra mais famosa "Frankenstein". A obra retrata o conflito enfrentado por Victor Frankenstein cientista que, na sua ânsia por descobrir o "elixir da vida", acaba se aventurando em uma audaciosa experiência científica, em que reunindo pedaços roubados de cadáveres e pretendendo dar vida à matéria morta, arquiteta uma nova criatura. A criatura, chamada apenas de "monstro", ganha vida mas acaba assombrando seu criador, que assustado com sua criação, foge do laboratório abandonando o monstro ${ }^{3}$.

O desenvolvimento da obra se dá a partir do conflito entre a atitude de Victor (de criar o monstro) e as próprias atitudes do monstro.

Como a história de Mary Shelley poderia se aproximar dos acontecimentos atuais?

A vontade de Victor Frankenstein de dar vida a pedaços de corpos inanimados é o que move esse paralelo. A interrupção do ciclo natural da vida, que se inicia com o nascimento e termina com a morte, leva a uma reflexão sobre a ideia da imortalidade, sobre o desejo de uma vida eterna, ou mesmo sobre o ideal de parar o tempo e manter-se naquele instante por muitos e muitos anos. Para alguns, um sonho; para outros, um pesadelo. De toda forma, a ideia causa, no mínimo, espanto e curiosidade.

Se no livro escrito por Shelley o dilema era a maneira como a vida do monstro havia sido criada, hoje a questão possui novos contornos, recaindo sobre a morte e seus múltiplos (re)signficados. Uma dessas ressignficações do morrer chamou a atenção do mundo em 2016 com o pedido de uma garota de 16 anos para manter seu corpo congelado após a morte e, recentemente (março de 2019), voltou ao debate por meio de uma decisão do Superior Tribunal de Justiça (STJ), que autorizou que uma filha mantivesse o corpo do pai congelado nos Estados Unidos.

A possibilidade levantada em ambos os casos se dá por meio da utilização de uma técnica chamada criogenia, que permite que corpos humanos sejam mantidos preservados a temperaturas negativas para que, no futuro, possam ser "descongelados" e reanimados.

\footnotetext{
${ }^{3}$ Não há no livro um nome para o "monstro", que ficou popularmente conhecido pelo sobrenome do seu criador, "Frankenstein".
} 
Se o descongelamento de corpos será capaz de reanimar as pessoas criopreservadas, a ciência ainda não é capaz de responder. Ficção científica ou não, a questão é delicada e gera muitos questionamentos.

Quando ocorreria o descongelamento? Em um prazo de 10, 100, 200 anos? A pessoa "descongelada" teria sua memória preservada? Qual seria a reação de uma pessoa que "dormisse" no mundo de hoje e só "acordasse" num futuro distante, sem nenhuma referência de tempo, espaço, pessoas conhecidas? A criogenia levaria a preservação do direito à vida a qualquer custo? Como é a regulação jurídica dos corpos que já estão congelados? Quais direitos devem ser assegurados à pessoa congelada e sua família? A criogenia levaria a relativização do conceito de vida e morte? A criopreservação do corpo humano acabaria por criar um novo Frankenstein?

Será a partir dessas inquietações que o presente artigo se desenvolverá. Buscando enfatizar seu aspecto transdisciplinar, a pesquisa terá por base dados secundários, extraídos de livros, artigos científicos e sites especializados, além da literatura clássica de Mary Shelley que apresentará o pano de fundo para o desenvolvimento da temática.

O objetivo geral será analisar a técnica da criogenia humana e suas principais implicações éticas e jurídicas na esfera sucessória, especialmente para responder ao seguinte problema de pesquisa: como garantir a vontade de criopreservação seja respeitada e também a existência de patrimônio do falecido (criopreservado) no futuro, para reestabelecer a vida quando (e se) possível? Para tanto, o artigo partirá de exemplos práticos de criogenia humana e reflexões literárias sobre o binômio vida-morte.

A ética da responsabilidade de Hans Jonas será utilizada como referencial teórico científico da pesquisa; já o referencial literário será a obra Frankenstein, de Mary Shelley.

A pesquisa será, com base no seu objetivo geral, exploratória. O método utilizado será o hipotético-dedutivo e as técnicas utilizadas serão o estudo de caso e a pesquisa bibliográfica.

\section{CRIOGENIA HUMANA: CONCEITO E CASOS PRÁTICOS}

“Tenho apenas 14 anos e não quero morrer, mas sei que vou morrer" (BBC, 2016). A frase é de uma adolescente britânica acometida por um tipo raro de câncer que, mesmo sabendo que estava prestes a morrer, tinha o desejo de continuar a viver. Seria esse um anseio comum 
de pacientes jovens com doenças terminais não fosse um fato importante: a menina pediu na Justiça o direito de ter seu corpo congelado após a sua morte.

O congelamento foi solicitado para que seu corpo pudesse ser preservado até o momento em que a cura para sua doença fosse descoberta, lhe devolvendo, com isso, a possibilidade de ter uma vida sadia.

O desejo da garota seria concretizado por meio da utilização de uma técnica conhecida como "criogenia humana". Muito utilizada para a criopreservação de embriões humanos, a criogenia passou a ser considerada também para a preservação de corpos humanos inteiros, na esperança de que, no futuro, as pessoas pudessem voltar à vida. Mas como isso seria possível?

A criogenia consiste na colocação do cadáver dentro de um tanque de nitrogênio líquido, a uma temperatura de $-196^{\circ} \mathrm{C}$. A ideia é que o corpo permaneça congelado para que futuramente possa ser trazido novamente à vida.

Uma pesquisa nos sites das duas maiores clínicas de criogenia humana do mundo Alcor Life Extension Fundation e Cryonics Institute - ambas nos EUA, apontou fatos que justificariam a técnica. Para a Alcor, há três elementos fundamentais: 1. A vida pode ser interrompida e reiniciada se sua estrutura básica for preservada; 2. A vitrificação ${ }^{4}$ pode preservar bem a estrutura biológica do corpo humano e; 3. A ciência é capaz de prever métodos para reparar a estrutura no nível molecular (ALCOR, 2019). Já o Cryonics Institute utiliza como principal argumento para a técnica a "perspectiva da imortalidade", cujo objetivo fundamental é dar às pessoas uma "segunda chance na vida" (CRYONICS, 2019).

As pessoas que passam pelo processo de criogenia, de acordo com informações da clínica norte-americana Alcor, não são consideradas mortas, mas “pacientes criopreservados”, pois a morte seria um estágio permanente e irreversível, contrariando a lógica da criogenia. Nesse sentido, o argumento de que a definição de morte foi alterada ao longo dos anos ganha corpo:

Há cem anos, a parada cardíaca era irreversível. As pessoas eram chamadas mortas quando seu coração parava de bater. Hoje acredita-se que a morte ocorra de 4 a 6 minutos após o coração parar de bater, porque após alguns minutos é difícil ressuscitar o cérebro (ALCOR, 2019). Tradução livre

\footnotetext{
${ }^{4}$ É o estado de não formação de gelo em temperaturas abaixo de 120 graus negativos.

5 Texto original: "A hundred years ago, cardiac arrest was irreversible. People were called dead when their heart stopped beating. Today death is believed to occur 4 to 6 minutes after the heart stops beating because after several minutes it is difficult to resuscitate the brain". (ALCOR, 2019).
} 
Apesar de não haver nenhuma evidência científica que comprove o sucesso da técnica, estima-se que cerca de 331 pessoas já tenham sido congeladas após a morte somente nas duas clínicas dos EUA. Além dos EUA, outro país em que há a utilização da técnica é a Rússia (REVISTA GALILEU, 2018).

O valor para a criopreservação de um corpo humano inteiro por tempo indeterminado, é bastante elevado. A Alcor pode cobrar em torno de 200 mil dólares para preservação do corpo inteiro, e 80 mil dólares para preservação somente do cérebro (que futuramente seria colocado em outro corpo). O Cryonics, por sua vez, cobra uma taxa única mínima de 28 mil dólares de seus membros vitalícios, devida no momento da morte. Referida taxa inclui a perfusão de vitrificação e armazenamento a longo prazo $^{6}$ (CRYONICS, 2019).

Médicos especialistas em criopreservação de embriões afirmam que embora a esta técnica (criopreservações de embriões), já muito utilizada, apresente uma taxa de sucesso de cerca de $60 \%$ após o descongelamento, a ideia de congelar um corpo humano inteiro para depois reanimá-lo ainda pode ser considerada como ficção científica.

O processo de criopreservação de corpos é, em tese, simples e envolve duas etapas: a primeira, da criopreservação em si; e a segunda, do "descongelamento" dos corpos. Com relação à primeira, não há grandes problemas e sua utilização é frequente nas clínicas; o grande desafio dessa etapa é o tempo gasto, pois para que a criogenia possa ter mais chances futuras, é preciso que o processo se inicie imediatamente após a morte, para que não haja comprometimento das células. Assim,

\begin{abstract}
Em tese, o processo de criopreservação é simples. Primeiro, o sangue é drenado do corpo e, em seguida, substituído por um líquido crioprotetor, o M-22, à base de glicerina. O objetivo desta substância química é evitar a formação de cristais de gelo que podem causar danos irreparáveis nas células do organismo. Depois, o cadáver é submetido, gradualmente, a baixas temperaturas até ser finalmente levado para um tanque de nitrogênio líquido, onde permanecerá de cabeça para baixo. O motivo para isso é que, em caso de vazamento, o cérebro fica protegido na base do freezer. (REVISTA GALILEU, 2018).
\end{abstract}

A segunda etapa da criogenia é o descongelamento do corpo para que este retome a vida. Tal etapa, entretanto, ainda é uma incógnita, mesmo para as clínicas especializadas, que ainda não sabem quando isso será possível. O questionamento maior em torno da segunda etapa

\footnotetext{
${ }^{6} \mathrm{O}$ valor é a taxa mínima, que pode sofrer acréscimos caso o paciente opte por serviços adicionais, como transporte do corpo.
} 
gira em torno da pergunta de como retomar a vida de um organismo complexo como o corpo humano.

Com relação aos exemplos práticos, no caso da garota britânica, apesar de uma resistência inicial por parte do seu pai, o desejo de ter o corpo criopreservado foi respeitado pela família. Entretanto, a equipe médica responsável relatou que ocorreram problemas no dia da morte da adolescente, manifestando preocupação com a maneira como o corpo foi preparado para o congelamento. Tal fato levou o juiz responsável pelo caso a sugerir que, futuramente, normas adequadas para a criopreservação de corpos humanos sejam discutidas por parlamentares britânicos (BBC, 2016).

Recentemente, em 26 de março de 2019, o STJ decidiu um caso sobre a questão da criogenia. Tratava-se de um pedido de uma filha para que o corpo do seu pai, criopreservado desde 2012, pudesse ser mantido nessa situação em uma clínica nos EUA.

A discussão chegou ao STJ pois as outras filhas do falecido não concordavam com a decisão da filha mais nova de criopreservar o corpo do pai, solicitando que este pudesse ser sepultado no Rio Grande do Sul, ao lado de sua ex-esposa. Em primeira instância o juiz autorizou o sepultamento do corpo, entretanto, em sede de apelação o Tribunal de Justiça do Rio de Janeiro reformou a sentença e determinou a continuidade do procedimento de criogenia (STJ, 20197).

$\mathrm{Na}$ análise dos embargos infringentes, o próprio TJRJ restabeleceu a sentença sob o argumento da ausência de autorização expressa deixada pelo pai em vida. Já a decisão do recurso encaminhado ao STJ trouxe a desnecessidade de autorização expressa, bastando, para tanto, a manifestação de um parente próximo. Além disso, destacou que a decisão não se tratava de decidir sobre o procedimento da criogenia em si, pois considera-se que a legislação brasileira, apesar de não tratar expressamente sobre o assunto, protege as manifestações de vontade do indivíduo, garantidas por meio da autonomia privada (STJ, 2019).

Nesse sentido, observa-se a ementa do mencionado julgamento, segundo a qual:

RECURSO ESPECIAL. AÇÃO ORDINÁRIA. 1. DISCUSSÃO TRAVADA ENTRE IRMÃS PATERNAS ACERCA DA DESTINAÇÃO DO CORPO DO GENITOR. ENQUANTO A RECORRENTE AFIRMA QUE O DESEJO DE SEU PAI, MANIFESTADO EM VIDA, ERA O DE SER CRIOPRESERVADO, AS RECORRIDAS SUSTENTAM QUE ELE DEVE SER SEPULTADO NA FORMA

\footnotetext{
${ }^{7}$ RESP 1.693.718/RJ. Disponível em: 〈http://www.stj.jus.br/SCON/jurisprudencia/toc.jsp>
} 
TRADICIONAL (ENTERRO). 2. CRIOGENIA. TÉCNICA DE CONGELAMENTO DO CORPO HUMANO MORTO, COM O INTUITO DE REANIMAÇÃO FUTURA. 3. AUSÊNCIA DE PREVISÃO LEGAL SOBRE O PROCEDIMENTO DA CRIOGENIA. LACUNA NORMATIVA. NECESSIDADE DE INTEGRAÇÃO DA NORMA POR MEIO DA ANALOGIA (LINDB, ART. $4^{\circ}$ ). ORDENAMENTO JURÍDICO PÁTRIO QUE, ALÉM DE PROTEGER AS DISPOSIÇÕES DE ÚLTIMA VONTADE DO INDIVÍDUO, COMO DECORRÊNCIA DO DIREITO AO CADÁVER, CONTEMPLA DIVERSAS NORMAS LEGAIS QUE TRATAM DE FORMAS DISTINTAS DE DESTINAÇÃO DO CORPO HUMANO EM RELAÇÃO À TRADICIONAL REGRA DO SEPULTAMENTO. NORMAS CORRELATAS QUE NÃO EXIGEM FORMA ESPECÍFICA PARA VIABILIZAR A DESTINAÇÃO DO CORPO HUMANO APÓS A MORTE, BASTANDO A ANTERIOR MANIFESTAÇÃO DE VONTADE DO INDIVÍDUO. POSSIBILIDADE DE COMPROVAÇÃO DA VONTADE POR QUALQUER MEIO DE PROVA IDÔNEO. LEGITIMIDADE DOS FAMILIARES MAIS PRÓXIMOS A ATUAREM NOS CASOS ENVOLVENDO A TUTELA DE DIREITOS DA PERSONALIDADE DO INDIVÍDUO POST MORTEM. 4. CASO CONCRETO: RECORRENTE QUE CONVIVEU E COABITOU COM SEU GENITOR POR MAIS DE 30 (TRINTA) ANOS, SENDO A MAIOR PARTE DO TEMPO EM CIDADE BEM DISTANTE DA QUE RESIDEM SUAS IRMÃS (RECORRIDAS), ALÉM DE POSSUIR PROCURAÇÃO PÚBLICA LAVRADA POR SEU PAI, OUTORGANDO-LHE AMPLOS, GERAIS E IRRESTRITOS PODERES. CIRCUNSTÂNCIAS FÁTICAS QUE PERMITEM CONCLUIR QUE A SUA MANIFESTAÇÃO É A QUE MELHOR TRADUZ A REAL VONTADE DO DE CUJUS. 5. CORPO DO GENITOR DAS PARTES QUE JÁ SE ENCONTRA SUBMETIDO AO PROCEDIMENTO DA CRIOGENIA HÁ QUASE 7 (SETE) ANOS. SITUAÇÃO JURÍDICA CONSOLIDADA NO TEMPO. POSTULADO DA RAZOABILIDADE. OBSERVÂNCIA. 6. RECURSO PROVIDO. (STJ, REsp 1693718 / RJ, Ministro Marco Aurélio Bellizze, DjE, 04/04/19).

Assim, a decisão do STJ defendeu o direito de o corpo permanecer no estado em que se encontrava, isto é, criopreservado em uma clínica nos EUA, reforçando que a manifestação da filha - que era a pessoa que tinha mais contato com o pai - seria suficiente para comprovar a sua vontade de ter o corpo criopreservado.

As duas situações, apesar de distintas em alguns pontos, trazem a mesma problemática: a negação da morte pelo ser humano, sua busca incessante pela imortalidade (ou, no mínimo, por um prolongamento da vida) e todas as implicações daí avindas, especialmente em matéria sucessória e patrimonial, pois sem este, no futuro, pode não haver como reestabelecer a vida.

\section{A ÉTICA DA RESPONSABILIDADE DE HANS JONAS E OS (RE)SIGNIFICADOS DA MORTE}

Victor Frankenstein, ao criar o monstro, não foi capaz de prever as consequências de seu experimento científico: naquele momento, bastava-lhe apenas a satisfação pessoal de criar 
algo inédito. Entretanto, o desenrolar da história demonstra que o resultado da sua obra lhe fugiu ao controle - o monstro passou a ter vontades próprias e a não obedecer ao seu criador.

A atitude de Victor se assemelha à ética tradicional - antropocêntrica - cujo relacionamento e "atuação sobre objetos não humanos não formava um domínio eticamente significativo" (JONAS, 2006, p. 35). Nesse sentido, ao realizar o experimento, Victor não considerou as consequências que poderiam daí surgir, principalmente com relação ao futuro, mas somente a satisfação pessoal no presente.

Da mesma maneira que a criação do monstro conduz à questionamentos éticos, a aplicação da técnica da criogenia humana também leva às mesmas controvérsias. Em primeiro lugar é preciso compreender a criogenia humana como um processo eminentemente antropocêntrico para, em seguida, perceber a (re)significação conferida à morte e, por fim, entender a responsabilidade humana neste processo.

A primeira questão está relacionada a como o ser humano se percebe na natureza. Nesse sentido, a criogenia pode ser considerada antropocêntrica por justamente negar o ciclo básico da vida, que começa com o nascimento e termina com a morte. Ao colocar uma alternativa a esse ciclo natural, o homem passa a se perceber em posição de domínio sobre a natureza e suas leis, colocando-se acima da própria natureza e utilizando-se de todo o seu conhecimento científico de maneira a corroborar tal aspecto.

O lado antropocêntrico também é reforçado pela crescente utilização e aperfeiçoamento da técnica. O chamado homo faber deixa de utilizar a técnica apenas por questão de necessidade e passa a utiliza-la como um caminho para se alcançar um fim já previamente estabelecido (pelo próprio ser humano), sem se preocupar com as consequências futuras de suas ações. A criogenia, nesse aspecto, é a utilização da técnica como instrumento para a busca pelo reestabelecimento da vida em um prazo ainda não determinado ou determinável.

A ética da responsabilidade, assim, deve ser discutida a partir da própria compreensão da morte. A partir do momento em que o ser humano utiliza-se de uma técnica para congelar o corpo com a promessa de um "ressurgir" futuro, ele está negando a própria natureza da vida e rotulando a morte como uma "falha orgânica evitável" ou, pelo menos, "de ser em princípio tratável e adiável por longo tempo" (JONAS, 2006, p. 58).

Ao negar o aspecto de naturalidade da morte, o ser humano passa a interferir, não só no ciclo natural da vida, mas também em toda a disposição humana. A própria procriação 
humana somente faz sentido pela existência da morte, a primeira é uma resposta da vida à última. Ao negar a morte, abre-se espaço para um mundo sem juventude, sem a surpresa do novo, daquele que estar por vir; cria-se um mundo apenas de conhecidos. Jonas, ao discorrer sobre o assunto afirma que

(...) talvez seja exatamente esta a sabedoria na severa disposição de nossa mortalidade: a de que ela nos oferece a promessa, continuamente renovada, com uma permanente oferta de alteridade como tal. (...) Esse eterno recomeçar, que só se pode obter ao preço do eterno terminar, pode muito bem ser a esperança da humanidade, que a protege de mergulhar no tédio e na rotina, sendo a sua chance de preservar a espontaneidade da vida (JONAS, 2006, p. 58-59).

Assim, ao tornar a morte evitável o ser humano quebra o ciclo natural e interfere na própria existência humana. Da mesma forma que Frankenstein perdeu o controle sobre sua criatura, não é possível prever o que acontecerá com os humanos após o descongelamento. Não há nenhuma garantia de que o experimento dê certo e, ainda, é preciso considerar que essas pessoas estarão totalmente deslocadas do seu tempo de origem e suas referências de mundo. Além disso, outro fator que também é colocado em xeque pelos próprios criogenistas é com relação à preservação da memória, pois não existe nenhuma certeza de que a memória dessas pessoas realmente vá ser preservada. Nesse sentido, aproxima-se, novamente, a criogenia do experimento de Frankenstein.

Um segundo dever ético a ser considerado é aquele que relaciona os atos presentes às futuras gerações. Qual o impacto que a conservação dessas pessoas trará para as gerações futuras? O mundo já caminha para um futuro de envelhecimento tardio da população, as taxas de natalidade vêm caindo ao longo dos anos e a expectativa de vida aumentando. Quando o ser humano passa a congelar pessoas e interromper o binômio vida-morte a consequência dessa ação para o futuro deve ser pensada. A nova ética não pode mais apenas se embasar no presente, ela deve considerar seus impactos para as futuras gerações: é dever humano conservar a natureza para que as gerações vindouras possam viver em um ambiente harmônico.

Quando, pois, a natureza nova do nosso agir exige uma nova ética de responsabilidade de longo alcance, proporcional à amplitude do nosso poder, ela então também exige, em nome daquela responsabilidade, uma nova espécie de humildade - uma humildade não como a do passado, em decorrência da pequenez, mas em decorrência da excessiva grandeza do nosso poder, pois há um excesso do nosso poder de fazer sobre o nosso poder de prever e sobre o nosso poder de conceder valor e julgar. Em vista do potencial quase escatológico dos nossos processos técnicos, o próprio conhecimento 
das consequências últimas é motivo para uma contenção responsável - a melhor alternativa, à falta da própria sabedoria (JONAS, 2006, p. 63-64).

$\mathrm{O}$ fato de o homem de hoje desconhecer as consequências reais do seu poder para as gerações futuras leva, inevitavelmente, a uma contenção responsável dos seus atos. Até que seja possível afirmar com certeza quais serão as consequências da criogenia para as gerações futuras, é preciso que a cautela guie as gerações presentes.

Da mesma forma como Victor Frankenstein passou parte de sua vida tentando controlar sua criatura e minimizar as consequências de seus atos, o desafio do homo faber é, assim, não se tornar refém do seu próprio poder.

As consequências da criogenia, entretanto, vão além das questões éticas. Vários pontos jurídicos devem ser observados. Desde a falta de uma regulamentação para a técnica até questões mais complexas como a transformação e (nova) aplicação do direito das sucessões.

\section{CRIOGENIA E O DIREITO DAS FAMÍLIAS E SUCESSÕES}

A família é a base da sociedade ${ }^{8}$, com relevante papel para o desenvolvimento social, político, econômico e cultural do País. É cediço que por anos a única forma de se constituir família se dava por meio do casamento (matrimônio), o que permitia a distinção entre famílias legítima e ilegítimas, dentre outras discriminações e escassez de direitos.

\footnotetext{
${ }^{8}$ Vide artigo 226, da Constituição da República Federativa do Brasil (CR/88):

Art. 226. A família, base da sociedade, tem especial proteção do Estado.

$\S 1^{\circ} \mathrm{O}$ casamento é civil e gratuita a celebração.

$\S 2^{\circ} \mathrm{O}$ casamento religioso tem efeito civil, nos termos da lei.

$\S 3^{\circ}$ Para efeito da proteção do Estado, é reconhecida a união estável entre o homem e a mulher como entidade familiar, devendo a lei facilitar sua conversão em casamento.

$\S 4^{\circ}$ Entende-se, também, como entidade familiar a comunidade formada por qualquer dos pais e seus descendentes.

$\S 5^{\circ}$ Os direitos e deveres referentes à sociedade conjugal são exercidos igualmente pelo homem e pela mulher.

$\S 6^{\circ} \mathrm{O}$ casamento civil pode ser dissolvido pelo divórcio.

$\S 7^{\circ}$ Fundado nos princípios da dignidade da pessoa humana e da paternidade responsável, o planejamento familiar é livre decisão do casal, competindo ao Estado propiciar recursos educacionais e científicos para o exercício desse direito, vedada qualquer forma coercitiva por parte de instituições oficiais ou privadas.

$\S 8^{\circ} \mathrm{O}$ Estado assegurará a assistência à família na pessoa de cada um dos que a integram, criando mecanismos para coibir a violência no âmbito de suas relações (BRASIL, 1988).
} 
Com o advento da Constituição da República Federativa do Brasil (CR/88), a família teve forte reconhecimento e proteção estatal, legitimando-se as variadas formas de constituição familiar. De fato, ocorreu uma transformação dos eixos da família, na qual, antes da CR/88, predominava-se a família singular (somente por meio do matrimônio), hierárquica (marcada pelo patriarcado) e transpessoal (foco na forma e não nos sujeitos); ao passo que após a CR/88, os eixos passaram a defender a pluralidade (de entidades familiares), a isonomia (entre homem, mulher e filhos) e a importância da eudemonística (foco nas pessoas envolvidas e na felicidade delas).

Dessa forma, percebe-se que, ao longo dos anos, o centro de importância da família se deslocou da forma para o indivíduo/sujeito. Não obstante, o ainda presente papel orgânico da instituição familiar, esta, agora, é encarada como o local primeiro de desenvolvimento do indivíduo, pois é em seu seio que cada um dos seus entes forma a sua personalidade e molda o seu caráter (ALMEIDA; RODRIGUES JÚNIOR, 2012).

Essas transformações advindas com a CR/88 e o reconhecimento do afeto como elemento basilar do Direito de Família ocasionaram uma significativa evolução do Direito das Famílias e do próprio ordenamento jurídico quanto a essa temática.

Dessa maneira, o direito das famílias e, consequentemente, das sucessões, têm sofrido significativas transformações nos últimos anos, principalmente por meio das mudanças do modelo mental social, cultural e jurisprudencial. Isso tem correlação com os avanços tecnológicos e científicos, capazes de alterar a realidade em que vivemos.

A autonomia privada e o elemento "afeto" têm alcançado força e destaque nas relações familiares e nas fundamentações jurídicas atreladas a essas temáticas.

Questões sobre a vida e a morte, suas repercussões, disposições e interferência estatal e da família e de seus membros são constantes pontos de análise e reflexão, mas os impasses permanecem, como no caso da criogenia humana e de suas implicações patrimoniais e sucessórias.

Maria Berenice Dias (2018) ensina que "o termo sucessão aplica-se a todos os modos derivados de aquisição do domínio. Indica o ato pelo qual alguém sucede a outrem, investindose, no todo em parte, nos direitos que lhe pertenciam". 
O Direito das Sucessões (causa mortis $^{9}$ ) disposto no Livro V do Código Civil (2002), em seu artigo primevo (art. $1.784^{10}$ ), trata da abertura da sucessão, momento em que, por força do princípio de Saisine (ficção jurídica criada para proteção aos herdeiros e para que as relações jurídicas não quedem-se sem titulares), automaticamente e imediatamente os bens do de cujus (falecido) transmitem-se aos herdeiros, a título universal (via de regra). Como expõe Maria Berenice Dias (2018), "com a morte ocorre o que se chama de abertura da sucessão: cessa a capacidade jurídica de uma pessoa em relação aos seus bens e começa a de outrem”.

Dessa forma, de acordo com a legislação em vigor no Brasil, no momento exato da morte, instantaneamente, todo o acervo patrimonial (herança) passa para a titularidade dos herdeiros (ainda que somente posteriormente, ante análise da ordem de vocação hereditária disposta no artigo $1.829^{11}$, CC/02, ou da disposição de última vontade válida, apurar-se-á quem deterá a qualidade de herdeiro em cada caso concreto, bem como o respectivo quinhão que fará jus).

Conforme preceitua o artigo $6^{\circ}$ do Código Civil ${ }^{12}$ vigente, a existência da pessoa natural termina com a morte. A prova da morte ocorre com a certidão de óbito, a partir o reconhecimento científico da morte cerebral ${ }^{13}$.

Todavia, em virtude dos avanços da ciência, o Direito das Sucessões tem sofrido nas últimas décadas, tanto no âmbito legal, quanto doutrinário e jurisprudencial, alterações e atualizações quanto a questões post mortem $^{14}$, como nos casos de testamento que preveem a

\footnotetext{
${ }^{9}$ A sucessão, isto é, a transferência de bens de uma pessoa a outra, pode se dar de duas formas: por vontade das partes ou em razão da morte. Se decorrer da manifestação de duas ou mais pessoas, em vida, se diz que a sucessão é inter vivos. Quanto aos direitos sucessórios, a transmissão só pode ocorrer em razão da morte, daí causa mortis (DIAS, 2018). Ou seja, a transferência de titularidade de direitos, obrigações e bens pode-se dar inter vivos (por exemplo: compra e venda de imóvel) ou causa mortis, quando da abertura da sucessão, em virtude do óbito de uma pessoa física.

${ }^{10}$ Artigo 1.784, CC/02: "Aberta a sucessão, a herança transmite-se, desde logo, aos herdeiros legítimos e testamentários".

${ }^{11}$ Artigo 1.829, CC/02: “A sucessão legítima defere-se na ordem seguinte:

I- $\quad$ Aos descendentes, em concorrência com o cônjuge sobrevivente, salvo se casado este com o falecido no regime da comunhão universal, ou no da separação obrigatória de bens (art. 1.640, parágrafo único); ou se, no regime da comunhão parcial, o autor da herança não houver deixados bens particulares,

II- Aos ascendentes, em concorrência com o cônjuge;

III- Ao cônjuge sobrevivente;

IV- Aos colaterais".

${ }^{12}$ Artigo $6^{\circ}, \mathrm{CC} / 02$ : "A existência da pessoa natural termina com a morte; presume-se esta, quanto aos ausentes, nos casos em que a lei autoriza a abertura de sucessão definitiva".

${ }^{13}$ Maria Berenice Dias (2018) elucida que os critérios para a declaração da morte migrou do coração para o cérebro, daí o termo morte cerebral. Contudo, a atribuição para a determinação do momento exato da morte é de competência da medicina e da bioética, não da Ciência jurídica.

${ }^{14}$ A expressão latina post mortem significa "depois da morte". Dicionário de latim.
} 
possibilidade de filho, futuro herdeiro, a ser concebida após a morte da pessoa natural (mais comum em caso de doação de material genético); bem como quanto à manifestação de vontade quanto ao desejo da forma de morrer em situações de doenças terminais ("testamento vital 15").

Nesse sentido, o Código Civil, dispõe o seguinte:

Art. 1.798. Legitimam-se a suceder as pessoas nascidas ou já concebidas no momento da abertura da sucessão.

Art. 1.799. Na sucessão testamentária podem ainda ser chamados a suceder: I - os filhos, ainda não concebidos, de pessoas indicadas pelo testador, desde que vivas estas ao abrir-se a sucessão;

II - as pessoas jurídicas;

III - as pessoas jurídicas, cuja organização for determinada pelo testador sob a forma de fundação.

Art. 1.800. No caso do inciso I do artigo antecedente, os bens da herança serão confiados, após a liquidação ou partilha, a curador nomeado pelo juiz.

$\S 1^{\circ}$ Salvo disposição testamentária em contrário, a curatela caberá à pessoa cujo filho o testador esperava ter por herdeiro, e, sucessivamente, às pessoas indicadas no art. 1.775 .

$\S 2^{\circ}$ Os poderes, deveres e responsabilidades do curador, assim nomeado, regem-se pelas disposições concernentes à curatela dos incapazes, no que couber.

$\S 3^{\circ}$ Nascendo com vida o herdeiro esperado, ser-lhe-á deferida a sucessão, com os frutos e rendimentos relativos à deixa, a partir da morte do testador.

$\S 4^{\circ}$ Se, decorridos dois anos após a abertura da sucessão, não for concebido o herdeiro esperado, os bens reservados, salvo disposição em contrário do testador, caberão aos herdeiros legítimos (BRASIL, 2002, grifos nossos).

Nesse sentido, no âmbito da doutrina, a obra "Reprodução Humana Assistida e parentalidade Responsável” (CARDIN, 2015), explica que as técnicas de reprodução humana assistida permitem o armazenamento e a conservação dos gametas - masculino e feminino- e de embriões desde que criopreservados à uma temperatura em média de (-) $176^{\circ} \mathrm{C}$. E mais:

\begin{abstract}
A inseminação post mortem é um procedimento realizado após o falecimento de um dos doadores dos gametas, e que pode gerar inúmeros conflitos no âmbito sucessório. A Resolução n. 2.121/2015 16 do Conselho Federal de Medicina (CFM) permite a mulher o direito de se inseminar após o falecimento de seu esposo ou companheiro, optando pela formação de uma família monoparental, ou o homem se utilizar de maternidade de sub-rogação para o mesmo desígnio.

Destaca-se que só será possível se houver a autorização prévia específica do(a) falecido(a) para o uso do material biológico criopreservado, de acordo com a legislação vigente, é o que dispõe a resolução n. 2.121/2015 (CARDIN, 2015, p.83).
\end{abstract}

15 Testamento vital é um tipo de "diretiva antecipada de vontade". Neste documento a pessoa manifesta a forma de intervenção médica e cientifica que deseja se submeter, ou não, quando e se estiver em situações de doenças terminais ou estado vegetativo ou de inconsciência. Geralmente dizem respeito a situações relacionadas as práticas da eutanásia, distanásia e ortotanásia.

${ }^{16}$ Revogada pela Resolução CFM n. 2168/2017, que manteve a redação anterior neste ponto. 
Ou seja, existe no Brasil previsão normativa (principalmente a Resolução do CFM) e reconhecimento de geração de nova vida a partir da criopreservação de gametas, em que pese haver profundas lacunas legislativas quanto a temática, o que gera insegurança e conflitos jurídicos.

Contudo, quando se está diante da criogenia humana, realizada para criopreservação do ser humano que faleceu e a sua posterior e incerta ressuscitação, não há ainda qualquer previsão legal expressa, nem quanto a forma da criogenia, nem tampouco quanto ao procedimento para o "retorno à vida", ou ainda quanto aos efeitos sucessórios de tal situação ainda considerada como impraticável (mas não, impossível).

De fato, Giselda Hironaka chegou a afirmar em sua obra "Morrer e suceder: passado e presente da transmissão sucessória concorrente" (2014), que "sim, a morte é uma das únicas certezas da vida humana". Entretanto, com os avanços da ciência, tal certeza pode vir a ser relativizada pela ressuscitação dos mortos, sobretudo em virtude da possibilidade (real e concreta) da criogenia humana, com inúmeros impactos de ordem social, econômica, psicológica e jurídicos ainda incertos.

No âmbito jurídico, o grande limbo que a criogenia e a ressuscitação carregam é o significativo impacto que ambas situações determinam quanto aos Direitos Sucessórios, uma vez que, no ordenamento jurídico brasileiro atual a abertura da sucessão se dá no momento exato da morte, com a transmissão automática e imediata dos direitos, deveres e patrimônio do de cujus aos seus herdeiros (legítimos ou testamentários).

Por isso, tanto a realidade da criogenia humana, quanto a possível ressuscitação futura, geram diversos questionamentos no âmbito jurídico, dentre os quais destacam-se os seguintes:

a) Qual é a natureza jurídica dos corpos que já estão congelados?

b) Como garantir que a vontade de criopreservação seja respeitada após a morte?

c) Quando e quem deve tomar a decisão de descongelamento do corpo criopreservado?

d) Como garantir existência de patrimônio do falecido (criopreservado) no futuro, para reestabelecer a vida quando (e se) possível?

e) Quais direitos devem ser assegurados à pessoa congelada e à sua família? 
f) A criogenia e a possibilidade teórica de ressuscitação futura levam à relativização do conceito de vida, de morte e da abertura da sucessão?

g) A criogenia leva à preservação do direito à vida a qualquer custo?

h) Como estabelecer o equilíbrio entre a Dignidade da Pessoa Humana do sujeito falecido e dos parentes e/ou herdeiros sobreviventes?

i) A criogenia e a possibilidade de ressuscitação futura extinguem ou relativizam o direito à morte e das sucessões?

Diante da lacuna legislativa, as respostas há algumas dessas perguntas (especialmente aquelas dos itens "a" à "d" acima) podem ser estabelecidas com o uso das normas relativas aos testamentos, à constituição de fundações, bem como com o recurso da analogia relativamente às normas e decisões já determinadas para a inseminação post mortem.

Nesse sentido, de acordo com o disposto no artigo 82 do Código Civil: “Art. 82. São móveis os bens suscetíveis de movimento próprio, ou de remoção por força alheia, sem alteração da substância ou da destinação econômico-social” (BRASIL, 2002).

Por isso, a resposta à pergunta acerca da natureza jurídica do corpo criopreservado é a de que este é um bem móvel sui generis, extra-commercium e indivisível ${ }^{17}$ (MOTA, 2016), suscetível, então, de ser transmitido como tal para os herdeiros e sucessores do de cujus.

Todavia, para responder às questões previstas nos itens "b", "c" e "d" acima, e garantir que a vontade de criopreservação seja respeitada após a morte, é necessário que, antes da morte, com fundamento no disposto no artigo 1.875 do Código Civil, a pessoa que pretende ter o seu corpo criopreservado para futura ressuscitação, estabeleça não apenas a sua vontade nesse sentido, mas também a dotação de bens livres para a constituição de uma fundação destinada ao desenvolvimento de pesquisas científicas com o seu próprio corpo criopreservado, bem como com a declaração expressa acerca dos critérios de administração da fundação (com a definição, por exemplo, de onde, quando e quem decidirá sobre a criopreservação e o descongelamento), com aparo no disposto no artigo 62 do Código Civil, segundo o qual:

\footnotetext{
${ }_{17}$ As autoras reconhecem a possibilidade de questionamento, inclusive do ponto de vista filosófico, de tal classificação excessivamente pragmática, sobretudo quando submetida ao contexto normativo do princípio da dignidade da pessoa humana, que pode ser projetada, inclusive, para o corpo inanimado. Todavia, este é o mesmo tratamento jurídico estabelecido quando há disposição testamentária com destinação do cadáver humano para fins de estudos científicos. Disponível em: < http://www.silviamota.com.br/visualizar.php?idt=5738966>. Acesso em: 13 abr 2019.
} 
Art. 62. Para criar uma fundação, o seu instituidor fará, por escritura pública ou testamento, dotação especial de bens livres, especificando o fim a que se destina, e declarando, se quiser, a maneira de administrá-la.

Parágrafo único. A fundação somente poderá constituir-se para fins de:

I - assistência social;

II - cultura, defesa e conservação do patrimônio histórico e artístico;

III - educação;

IV - saúde;

V - segurança alimentar e nutricional;

VI - defesa, preservação e conservação do meio ambiente e promoção do desenvolvimento sustentável;

VII - pesquisa científica, desenvolvimento de tecnologias alternativas, modernização de sistemas de gestão, produção e divulgação de informações e conhecimentos técnicos e científicos;

VIII - promoção da ética, da cidadania, da democracia e dos direitos humanos;

IX - atividades religiosas; $\mathrm{e}$

X - (VETADO). (Incluído pela Lei no 13.151, de 2015). (BRASIL, 2002).

Tudo isso não determina, contudo, resposta para todas as outras indagações acima. Mas isso é uma outra história que não pode ter o mesmo destino e fim da história do Frankestein.

\section{CONCLUSÕES}

Inúmeros são os questionamentos e inseguranças quanto ao próprio procedimento da criogenia, ainda mais sobre o possível e incerto "retorno à vida", bem como quanto aos direitos de tal hipótese, principalmente no âmbito do Direito de família e sucessões.

Dessa forma, tal pesquisa é relevante e almeja fomentar o debate sobre o tema, a fim de elucidar alguns dos questionamentos aqui apontados, bem como auxiliar o melhor caminho para as disposições normativas e interpretações judiciais vindouras e necessárias.

Diante de todos os questionamentos éticos e jurídicos apresentados em torno da técnica de criogenia humana, a saída mais conveniente - ao menos por ora - seria a manifestação expressa do indivíduo por meio do testamento vital. Acredita-se que o instrumento é a forma mais segura de ter a vontade do indivíduo preservada após o seu falecimento.

Além disso, de maneira a assegurar os direitos sucessórios - pois o descongelamento é evento futuro e incerto - a opção pela fundação em testamento também deve ser cogitada, de maneira a garantir bens que possibilitem a continuidade da sua vida. 
No tocante aos aspectos éticos que permeiam o tema, é importante que se considere a ética da responsabilidade para com as futuras gerações, principalmente com relação ao momento do descongelamento dos corpos. Não ter uma certeza sobre as reais consequências desse experimento científico, inevitavelmente, retoma a pergunta inicial do texto: estaria a ciência criando um novo Frankenstein?

\section{REFERÊNCIAS}

ALMEIDA, Renata Barbosa de; RODRIGUES JÚNIOR, Walsir Edson. Direito Civil: família. 2 ed. São Paulo: Atlas, 2012, 588 p.

ALCOR LIFE EXTENSION FUNDATION. Disponível em: < https://www.alcor.org/ > Acesso em: 01 abr. 2019.

BBC Brasil. Antes de morrer, adolescente britânica com câncer ganha na Justiça direito de ter corpo congelado. Disponível em: < http://www.bbc.com/portuguese/internacional$\underline{38024415}>$ Acesso em: 18 nov. 2016.

BRASIL. Constituição (1988). Constituição da República Federativa do Brasil. Brasília: Senado Federal, Centro Gráfico, 1988.

BRASIL. Lei n. 10.406, de 10 de janeiro de 2002. Institui o Código Civil. Disponível em: < http://www.planalto.gov.br/ccivil_03/leis/2002/L10406compilada.htm > Acesso em: 11 abr. 2019.

BRASIL. Superior Tribunal de Justiça. Recurso Especial. REsp 1693718 / RJ. Relator: Marco Aurélio Bellizze. Diário de Justiça Eletrônico, 04 de abril de 2019. Disponível em: < http://www.stj.jus.br/SCON/jurisprudencia/toc.jsp > Acesso em: 10 abr. 2019.

CARDIN, Valéria Silva Galdino. Reprodução Humana Assistida e parentalidade responsável: conflitos e convergência entre os direitos brasileiros e português. - 1 ed. Birigui, SP: Boreal Editora, 2015.

CORPO de brasileiro permanecerá congelado nos Estados Unidos, decide terceira turma. STJ Notícias (2019). Disponível em: <

http://www.stj.jus.br/sites/STJ/default/pt_BR/Comunica\%C3\%A7\%C3\%A3o/noticias/Not\%C 3\%ADcias/Corpo-de-brasileiro-permanecer\%C3\%A1-congelado-nos-Estados-Unidos,decide-Terceira-Turma > Acesso em: 02 abr. 2019.

CRIOGENIA já é utilizada na vida real. Revista Galileu (2018). Disponível em: < https://revistagalileu.globo.com/Ciencia/noticia/2018/07/criogenia-ja-e-utilizada-na-vida-realconheca-como-funciona-tecnica.html > Acesso em: 02 abr. 2019.

CRYONICS INSTITUTE. Disponível em: < https://www.cryonics.org/ > Acesso em: 01 
abr. 2019.

DIAS, Maria Berenice. Manual das sucessões. - 5. ed. rev., atual. e ampl. - Sã Paulo: Thomson Reuters Brasil, 2018.

HIRONAKA, Giselda Maria Fernandes Novaes. Morrer e suceder: passado e presente da transmissão sucessória concorrente. - 2 ed. rev. - São Paulo: Editora Revista dos Tribunais, 2014.

JONAS, Hans. O princípio responsabilidade: ensaio de uma ética para a civilização tecnológica. Rio de Janeiro: Contraponto/PUC-RIO, 2006.

MOTA, Sílvia. O cadáver e sua natureza jurídica. 2016. Sitio eletrônico. Disponível em: < http://www.silviamota.com.br/visualizar.php?idt=5738966 >. Acesso em: 13 abr 2019.

NAMBA, Edison Tetsuzo. Manual da bioética e biodireito. - 2 ed. São Paulo: Atlas, 2015.

SHELLEY, Mary. Frankenstein ou o Prometeu moderno. Tradução Adriana Lisboa. 2 ed. Rio de Janeiro: Nova Fronteira, 2014.

VIEIRA, Tereza Rodrigues; CARDIN, Valéria Silva Galdino; GOMES, Luiz Geraldo do Carmo (org.). Bioética e cinema. - 2 ed. Maringá: Editora Miraluz, 2017. 330p. 